\title{
Effects of an anionic surfactant (FFD-6) on the energy and information flow between a primary producer (Scenedesmus obliquus) and a consumer (Daphnia magna)
}

\author{
M. Lürling $\cdot$ H. J. de Lange $\cdot$ E. T. H. M. Peeters
}

Accepted: 16 June 2011/Published online: 30 June 2011

(C) The Author(s) 2011. This article is published with open access at Springerlink.com

\begin{abstract}
The effects of a commercially available anionic surfactant solution (FFD-6) on growth and morphology of a common green alga (Scenedesmus obliquus) and on survival and clearance rates of the water flea Daphnia magna were studied. The surfactant-solution elicited a morphological response (formation of colonies) in Scenedesmus at concentrations of $10-100 \mu \mathrm{l} \mathrm{l}^{-1}$ that were far below the No Observed Effect Concentration (NOEC) value of 1,000 $\mu \mathrm{l}$ $1^{-1}$ for growth inhibition. The NOEC-value of FFD-6 for colony-induction was $3 \mu \mathrm{l}^{-1}$. Daphnia survival was strongly affected by FFD-6, yielding $\mathrm{LC}_{50-24 \mathrm{~h}}$ and $\mathrm{LC}_{50-48 \mathrm{~h}}$ of 148 and $26 \mu \mathrm{l}^{-1}$, respectively. In addition, clearance rates of Daphnia feeding on unicellular Scenedesmus were inhibited by FFD-6, yielding a 50\% inhibition $\left(\mathrm{EC}_{50-1.5 \mathrm{~h}}\right)$ at $5.2 \mu \mathrm{l}^{-1}$ with a NOEC of $0.5 \mu \mathrm{l}^{-1}$. When Daphnia were offered FFD-6-induced food in which eightcelled colonies $(43 \times 29 \mu \mathrm{m})$ were most abundant, clearance rates $\left(\sim 0.14 \mathrm{ml}_{\text {ind. }}^{-1} \mathrm{~h}^{-1}\right)$ were only $25 \%$ the rates of animals that were offered non-induced unicellular $(15 \times$ $5 \mu \mathrm{m})$ Scenedesmus $\left(\sim 0.56 \mathrm{ml}\right.$ ind. $\left.^{-1} \mathrm{~h}^{-1}\right)$. As FFD-6 concentrations in the treated food used in the experiments
\end{abstract}

M. Lürling $(\varangle) \cdot$ H. J. de Lange · E. T. H. M. Peeters Aquatic Ecology and Water Quality Management Group, Department of Environmental Sciences, Wageningen University, P.O. Box 47, 6700 AA Wageningen, The Netherlands e-mail: miquel.lurling@wur.nl

M. Lürling

Department of Aquatic Ecology, Netherlands Institute of Ecology (NIOO-KNAW), Droevendaalsesteeg 10, 6708 PB Wageningen, The Netherlands

H. J. de Lange

Centre for Ecosystem Studies, Alterra, Wageningen University and Research Centre, P.O. Box 47, 6700 AA Wageningen,

The Netherlands were far below the NOEC for clearance rate inhibition, it is concluded that the feeding rate depression was caused by the altered morphology of the Scenedesmus moving them out of the feeding window of the daphnids. The surfactant evoked a response in Scenedesmus that is similar to the natural chemically induced defensive reaction against grazers and could disrupt the natural information conveyance between these plankton organisms.

Keywords Colony formation - Induced defense . Info-disruption $\cdot$ Morphology $\cdot$ Plankton interaction

\section{Introduction}

The phytoplankton-zooplankton interaction is of major importance for the functioning of freshwater systems, as it represents the crucial transfer from plant material into animal biomass. Especially members of the genus Daphnia play an important role in lentic ecosystems as phytoplankton grazers by linking limnetic primary production and higher trophic levels (Tollrian and Dodson 1999). Any effects on Daphnia abundance and feeding activity will spread out over the food web, where feeding impairment in particular might result in proliferation of phytoplankton biomass and a dramatic shift from clear water to a turbid state (Scheffer et al. 1993, 2001).

It is already known for years that filtering rates of Daphnia might be a very sensitive indicator for toxic stress (Kersting and van der Honing 1981). Because filtration requires coordination of the movements of appendages by the nervous system, especially neurotoxicants, such as insecticides, may at sub lethal concentrations cause a decrease in Daphnia filtering rates (e.g. Gliwicz and Sieniawska 1986; Fernández-Casselderry et al. 1994; 
Hartgers et al. 1999; Villarroel et al. 1999; Christensen et al. 2005; Barata et al. 2008; Pestana et al. 2010). However, feeding efficiency also depends on the palatability of the food source. Wealthy information exists on effects of phytoplankton size and morphology on Daphnia filtering rates, where cells exceeding the maximum size of ingestible particles will be inedible for Daphnia (Lampert 1987). When grazers such as Daphnia graze upon cells of the common green alga Scenedesmus, chemicals released during the grazing process promote the formation of colonies to sizes beyond the ingestion capacity of the grazers (Lürling 2003). This chemically induced morphological change in the algal food species not only hampers food intake, but also impairs Daphnia growth and reproduction (Lürling and Van Donk 1996).

Recently, it has been observed that the commercially available anionic surfactant FFD-6 (Skalar chemical) could transform the unicellular green alga Scenedesmus obliquus into colonies (Lürling and Beekman 2002; Lürling 2006). The surfactant FFD-6 induced a response similar to the one evoked by the natural information conveying chemicals. These natural active substances have been extracted from Daphnia and could be identified as different aliphatic sulfates and sulfamates showing strong structural similarity with synthetic anionic surfactants (Yasumoto et al. 2005, 2006, 2008a, b). Hence, despite various anionic surfactants have been classified as not dangerous to the environment with respect to their effect on Daphnia (Verge and Moreno 2000), the FFD-6-induced morphological effect might indicate potential adverse effects on the energy-flow from algae to higher trophic levels at concentrations previously thought to be safe. Therefore, in the current study we tested the hypothesis that FFD-6 induced colonies of the green alga Scenedesmus obliquus decrease the filtering rate of the grazer Daphnia magna.

\section{Materials and methods}

\section{Organisms}

The green alga Scenedesmus obliquus (Turpin) Kützing SAG 276/3a (originating from the culture collection of the University of Göttingen, Germany) was maintained in a round-glass 1.01 chemostat system on a standard algal growth medium (Lürling and Beekman 2006). The chemostat system received algal growth medium with a dilution rate of $1.1 \mathrm{day}^{-1}$. The culture vessel was illuminated with a constant incident irradiance of $100 \mu \mathrm{mol}$ quanta $\mathrm{m}^{-2} \mathrm{~s}^{-1}$ provided by circular fluorescent tubes (Philips TLEM $40 \mathrm{~W} /$ 33RS) and was placed in a temperature-controlled chamber at $20^{\circ} \mathrm{C}$. The chemostat was aerated with sterilized $(0.2-\mu \mathrm{m}$ membrane filter) and moistened air flowing from the bottom to the top of the vessel ensuring optimal mixing of the algal population. Under these conditions, the algal population was mainly unicellular with on average 1.5 cells per colony and a mean particle volume of $\sim 150 \mu \mathrm{m}^{3}$.

The grazer Daphnia magna Straus has been isolated from Lake Zwemlust (The Netherlands) and isofemale lineages have been cultured in 11 vessels containing artificial RT-medium (Tollrian 1993) at a constant temperature of $20^{\circ} \mathrm{C}$ ( $\mathrm{pH} \mathrm{7.5-8.0).} \mathrm{The} \mathrm{animals} \mathrm{were} \mathrm{fed} \mathrm{three} \mathrm{times} \mathrm{a}$ week ad libitum with $S$. obliquus harvested from the chemostat systems.

\section{Surfactant}

The anionic surfactant FFD-6 was obtained from Skalar BV (Breda, The Netherlands). The product (Skalar 00429040590) was delivered as a FFD-6 surfactant solution that consists of $55 \%$ water and $45 \%$ mono- and didodecyl disulphanated diphenyloxide, sodium salt (Lürling 2006). The compound was tested without the use of additional solvents.

\section{Effect of FFD-6 on S. obliquus}

The effect of FFD-6 on growth and morphology of $S$. obliquus was tested by running batch experiments in $100 \mathrm{ml}$ Erlenmeyer flasks that contained $50 \mathrm{ml}$ algal growth medium with different concentrations of FFD-6. The surfactant FFD-6 was added at final concentrations of $0,10^{\circ}, 10^{1}, 10^{2}$,

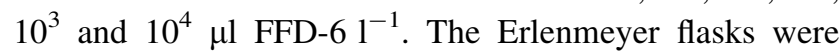
closed with cellulose-plugs. Controls and treatments were run for $48 \mathrm{~h}$ in triplicates and the initial algal concentration

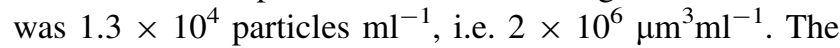
flasks were incubated in continuous light of $125 \mu \mathrm{mol}$ quanta $\mathrm{m}^{-2} \mathrm{~s}^{-1}$ at $20^{\circ} \mathrm{C}$ on a rotating shaking device (80 rpm). After $48 \mathrm{~h}$ the algal concentrations and size distributions were determined in the range $2.5-25 \mu \mathrm{m}$ equivalent spherical diameter (ESD) using a Coulter ${ }^{\circledR}$ Multisizer II (capillary $100 \mu \mathrm{m}$ orifice width, Coulter Electronics Limited, Luton, England). The mean particle volumes (MPV) calculated from Coulter data were statistically compared using a one-way ANOVA in the statistical tool pack SPSS with surfactant concentration as the fixed factor. In addition to measurements of MPV, the numbers of cells per colony were determined microscopically by counting at least 100 aggregates (i.e. unicells and colonies) in sub samples that were preserved with Lugol's fixative $(10 \%$ $\mathrm{v} / \mathrm{v})$. The mean numbers of cells per colony were statistically compared using a one-way ANOVA, followed by a Tukey test to distinguish the significantly different means.

Growth rates were calculated from the increase in algal biovolume measured with the Coulter Multisizer II using the equation $\mu=\left\{\ln \left(\mathrm{V}_{\mathrm{t}}\right)-\ln \left(\mathrm{V}_{0}\right)\right\} \times \Delta \mathrm{t}^{-1}$, where 
$\mathrm{V}_{\mathrm{t}}=$ the final algal biovolume $\left(\mu \mathrm{m}^{3} \mathrm{ml}^{-1}\right), \mathrm{V}_{0}=$ the initial algal biovolume and $\Delta t=$ the incubation time (d). Cellbased growth rates were calculated from the number of particles determined by the Coulter Multisizer II and the mean number of cells per particle determined by microscope. The chlorophyll- $a$ concentration $\left(\mu \mathrm{g}^{-1}\right)$ and photosynthetic activity of the algae $\left(\Phi_{\mathrm{PSII}}\right)$ was measured with the PHYTO-PAM phytoplankton analyzer (Heinz Walz $\mathrm{GmbH}$, Effeltrich, Germany) using a new reference spectrum for the green alga $S$. obliquus.

For biovolume- and cell-based growth rates, chlorophyll- $a$ concentrations and photosynthetic activities, $\mathrm{EC}_{50}$ values were determined by non-linear regression (three parameter logistic model) using an iterative process of parameter value adjustments in the toolpack SigmaPlot 2000 for Windows version 6.00. All endpoints were statistically evaluated running one-way ANOVA followed by a Tukey test to distinguish the significantly different means in the statistical tool pack SPSS. The No Observed Effect Concentration (NOEC) was defined as the highest dose at which there was statistically no effect found, while higher dose caused an effect.

In a second biotest, the $1 / 2$ max-MPV values (i.e. FFD- 6 concentration causing a $50 \%$ increase in the mean particle volume, MPV, of the maximum MPV reached in the treatments) for colony formation in $S$. obliquus was determined. Inocula of $S$. obliquus from the chemostat (with $1.85 \pm 0.07$ cells colony ${ }^{-1}$ ) were transferred into $100 \mathrm{ml}$ Erlenmeyer flask that contained $50 \mathrm{ml}$ algal growth medium without (controls) or with FFD-6 (treatments) in the range $10^{0}-10^{1} \mu \mathrm{FFD}-61^{-1}$ at $1 \mu 1 \mathrm{l}^{-1}$ intervals. The initial algal concentration was $2 \times 10^{6} \mu \mathrm{m}^{3} \mathrm{ml}^{-1}$ and four replicates per treatment were used. At the start of the experiment and after $48 \mathrm{~h}$ incubation under conditions as outlined above the algal concentrations and size distributions were determined in the range 2.5-25 $\mu \mathrm{m}$ ESD using the Coulter Multisizer II. The $1 / 2$ max-MPV value for colony formation was determined by non-linear regression using a four parameter logistic model. Because Levene's test indicated that equal variances could not be assumed, MPV was statistically compared by a non-parametric KruskalWallis test. Dunnett's T3 test was used for the post-hoc comparison in order to control for Type I error across the pairwise comparisons.

\section{Effect of FFD-6 on Daphnia survival}

A cohort of D. magna was created by transferring newborns from the stock cultures into new jars with fresh RTmedium. The animals were fed S. obliquus $(\sim 10 \mathrm{mg} \mathrm{C}$ $1^{-1}$ ) from the chemostat every other day. Neonates born on the same day in these cultures were transferred to new jars with fresh RT-medium and S. obliquus food. After 3 days, the juveniles were collected on a $150 \mu \mathrm{m}$ sieve, rinsed with RT-medium, and transferred to a beaker with fresh RTmedium. Groups of 15 specimens were selected from the beaker and placed in $250 \mathrm{ml}$ beakers with $150 \mathrm{ml}$ freshly prepared RT-medium without any food. In these beakers the animals were exposed for $48 \mathrm{~h}$ to FFD- 6 in the concentrations $0,10^{-1}, 10^{0}, 10^{1}, 10^{2}, 10^{3}$ and $10^{4} \mu \mathrm{FFD}$ $61^{-1}$. The beakers were incubated at $20^{\circ} \mathrm{C}$. The experiment was run in triplicate and the number of surviving animals was recorded after $24 \mathrm{~h}$ and $48 \mathrm{~h}$.

\section{Effect of FFD-6 on Daphnia clearance rates}

A grazing experiment was performed to study the effect of FFD-6 on clearance rates of D. magna ( $c f$. Lürling and Verschoor 2003). Juvenile three day old D. magna were collected on a $150 \mu \mathrm{m}$ sieve, rinsed with RT-medium, and transferred to a $250 \mathrm{ml}$ beaker with $150 \mathrm{ml}$ fresh RTmedium. Animals were randomly selected from the beaker and pipetted individually in a drop of medium to $3 \mathrm{ml}$ vials on 24-welled culture plates that contained $2.5 \mathrm{ml}$ of $S$. obliquus in RT-medium $\left(20 \mu \mathrm{g}\right.$ chlorophyll- $\left.a 1^{-1}\right)$ and FFD-6 concentrations of $0,0.5,5,50,500$ and $5000 \mu \mathrm{l}^{-1}$. Each vial contained one animal. The algae were mainly unicellular with a mean particle volume of $70 \mu \mathrm{m}^{3}$. For each concentration three Daphnia were selected, while one vial received only a drop of medium from the beaker and served as animal-free controls. The culture plates were incubated at $20^{\circ} \mathrm{C}$ in the dark for $1.5 \mathrm{~h}$. Every 30 -min. settled material was resuspended by gently using a pipette and blow some water with it. Initially and after $1.5 \mathrm{~h}$, the samples were analyzed on chlorophyll- $a$ content using the PHYTO-PAM. Clearance rates (CR, in $\mathrm{ml}$ ind..$^{-1} \mathrm{~h}^{-1}$ ) were calculated using the equation $\mathrm{CR}=\left\{\ln \left(\mathrm{A}_{\mathrm{C}}\right)-\ln \left(\mathrm{A}_{\mathrm{T}}\right)\right\} \times$ $\Delta \mathrm{t}^{-1} \times \mathrm{V} / \mathrm{N}$ where $\mathrm{A}_{\mathrm{C}}$ is the algal concentration (chlorophyll- $a$ in $\mu \mathrm{g}^{-1}$ ) in controls, $\mathrm{A}_{\mathrm{T}}$ is the algal concentration in the treatments, $\Delta t$ is the time $(1.5 \mathrm{~h}), V$ is the culture volume $(2.5 \mathrm{ml})$ and $N$ is the number of animals ( $=1$ per vial). The concentration causing 50\% inhibition of the clearance rates $\left(\mathrm{EC}_{50}\right.$ value) was determined by non-linear regression. The body-length of each animal was measured under a dissecting microscope $(40 \times$ magnification) from just above the eye until the base of the tail spine. CR were compared by Kruskal-Wallis test and Dunnett's T3 test was used as follow up test for the pairwise comparisons.

Effect of FFD-6 induced colonies on Daphnia clearance rates

A second grazing experiment was conducted to investigate the effect of unicellular $S$. obliquus and surfactant-induced colonial S. obliquus on D. magna clearance rates. Colonial S. obliquus were obtained by incubating inocula from the 
chemostat culture in $100 \mathrm{ml}$ Erlenmeyer flasks containing $50 \mathrm{ml}$ medium in the absence (controls) or presence of FFD-6 $\left(10 \mu \mathrm{l}^{-1}\right)$. Controls and treatments were run for $48 \mathrm{~h}$ in quadruplicates as outlined above with identical initial algal concentration of $\left(1.3 \times 10^{4}\right.$ particles $\mathrm{ml}^{-1}$, i.e. $2 \times 10^{6} \mu \mathrm{m}^{3} \mathrm{ml}^{-1}$ ). Both mean particle volumes (MPV, in $\mu \mathrm{m}^{3}$ ) and the number of cells per colony were statistically compared using a $t$-test. Length and width dimensions of unicells, four-celled colonies and eight-celled colonies were measured using a Leica Quantimet $500 \mathrm{MC}$ image analyzer coupled with a Nikon light-microscope at $500 \times$ magnification.

The grazing experiment was performed as described previously, but with two food concentrations (0.1 and $0.2 \mathrm{mg} \mathrm{C}^{-1}$ ) and two food types (unicellular and colonial). The experiment was performed with lower food concentrations than the previous one to have maximal clearance rates and to avoid any potential influence of FFD-6 transported with the algal suspensions, i.e. maximally 0.05 and $0.1 \mu \mathrm{lFFD}-61^{-1}$ was transferred. For each treatment, five Daphnia were selected from a cohort of juvenile 2-day-old $D$. magna, and five other vials received only a drop of medium from the beaker and served as animal-free controls. The culture plates were incubated for $1.5 \mathrm{~h}$ in the dark at $20^{\circ} \mathrm{C}$, and hereafter clearance rates were calculated as outlined above. Clearance rates were statistically compared running a two-way ANOVA with food concentration and food morphology (i.e. unicells or colonies) as the fixed factors in the statistical tool pack SPSS.

\section{Results}

\section{Effect of FFD-6 on S. obliquus}

Exposure of $S$. obliquus to a concentration gradient of FFD-6 yielded significant differences in the volume- (oneway ANOVA: $\left.F_{5,12}=24.9 ; P<0.001\right)$ and cell-based $\left(F_{5,12}=15.0 ; P<0.001\right)$ growth rates (Fig. 1$)$. Tukey's test disclosed two homogenous groups for each endpoint: (1) the concentrations $0,10^{0}, 10^{1}, 10^{2}$, and $10^{3} \mu$ FFD$61^{-1}$ and (2) the treatments with a concentration of $10^{4} \mu \mathrm{l}$ FFD-6 $1^{-1}$. Volume-based growth rates in the range $0-10^{3}$ $\mu$ FFD-6 $1^{-1}$ were similar $\left(1.04 \pm 0.08 \mathrm{~d}^{-1}\right)$, but they were significantly lower in the $10^{4} \mu$ FFD- $61^{-1}$ treatment $\left(0.52 \pm 0.08 \mathrm{~d}^{-1}\right)$. A tendency of higher cell multiplication rates in the range $0-10 \mu \mathrm{l}$ FFD- $61^{-1}$ was observed (Fig. 1), but cell-based growth rates were similar in $0-10^{3}$ $\mu$ FFD-6 $\mathrm{l}^{-1}\left(0.90 \pm 0.13 \mathrm{~d}^{-1}\right)$, and only significantly lower in $10^{4} \mu \mathrm{FFD}-6 \mathrm{l}^{-1}\left(0.37 \pm 0.03 \mathrm{~d}^{-1}\right)$. Chlorophyll$a$ concentrations were significantly higher in $0,10^{0}, 10^{1}$, and $10^{2}$ FFD- $61^{-1}\left(1395 \pm 80 \mu \mathrm{g} \mathrm{l}^{-1}\right)$ than in the $10^{4} \mu \mathrm{l}$

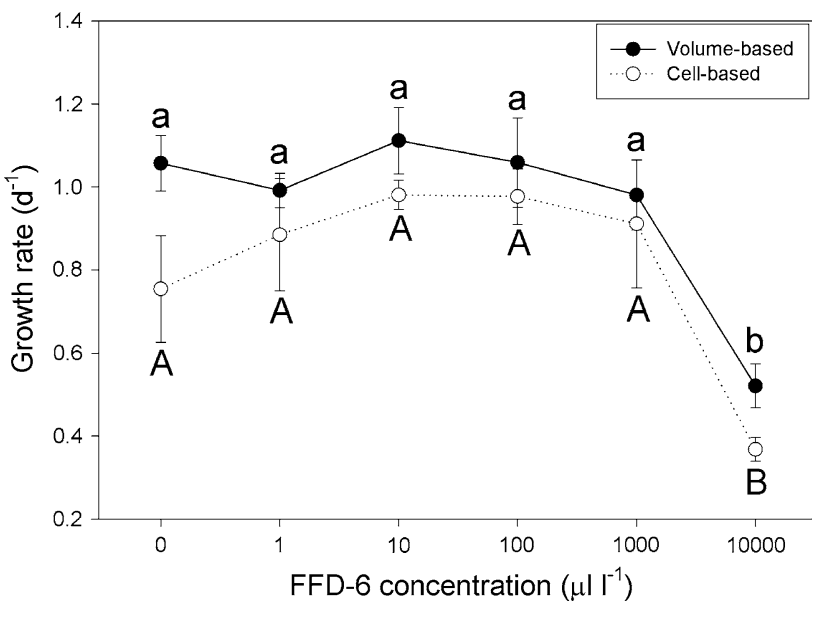

Fig. 1 Growth rates $\left(\mu, \mathrm{d}^{-1}\right)$ based on the increase in biovolume (filled symbols) and on the increase in cell numbers (open symbols) for Scenedesmus obliquus exposed for $48 \mathrm{~h}$ to different concentrations of the surfactant FFD-6. Error bars indicate one standard deviation $(N=3)$, while similar symbols $(a, b$ and $A, B)$ indicate homogeneous groups that are not different at the $95 \%$ level (Tukey test)

FFD-6 $\mathrm{l}^{-1}$ treatment $\left(574 \pm 11 \mu \mathrm{g} \mathrm{l}^{-1}\right)$. The chlorophyll$a$ concentration at $10^{3} \mu \mathrm{l}$ FFD-6 $1^{-1}\left(1063 \pm 32 \mu \mathrm{g} \mathrm{1^{-1 }}\right)$ was significantly different from the $0,10^{0}$ and $10^{4} \mu \mathrm{FFD}$ $61^{-1}$ treatments. The $\Phi_{\text {PSII }}$ was similar in the range 0 to $10^{3} \mu \mathrm{FFD}-61^{-1}(0.72 \pm 0.01)$, but significantly lower in the $10^{4} \mu 1$ FFD- $61^{-1}$ treatment $(0.47 \pm 0.03)$. The corresponding $\mathrm{EC}_{50}$ values for volume- and cell-based growth rates as well as those based on PHYTO-PAM derived chlorophyll- $a$ concentrations and photosynthetic activities are given in Table 1. The volume- and cell based growth rates had a NOEC of $10^{3} \mu \mathrm{l}$ FFD- $61^{-1}$, chlorophyll$a$ concentration a NOEC of $10^{2} \mu 1$ FFD-6 $1^{-1}$ and $\Phi_{\text {PSII }}$ a NOEC $>10^{4} \mu 1$ FFD- $61^{-1}$.

Not only growth rates, but also $S$. obliquus morphology was affected by the exposure to FFD-6 as significant differences were found in MPV $\left(F_{5,12}=25.9 ; P<0.001\right)$ and the mean number of cells per colony $\left(F_{5,12}=32.7\right.$; $P<0.001$ ) (Fig. 2). Both the MPV and the mean number of cells per colony were significantly higher at 10-1000 $\mu \mathrm{l}$ FFD- $61^{-1}$ compared to controls and the 1 and $10^{4} \mu 1$ FFD$61^{-1}$ treatments (Fig. 2). Focusing on the range between 1 and $10 \mu \mathrm{lFF}-61^{-1}$ revealed a sigmoid shaped response curve for colony formation in S. obliquus (Fig. 3). The Kruskal-Wallis test indicated significant differences in MPV $\left(\chi^{2}=32.6 ; \quad P<0.001\right)$. Because a significant increase in MPV was found at $4 \mu \mathrm{lFD}-61^{-1}$ compared to the control, but not at $3 \mu \mathrm{lFFD}-61^{-1}$, the latter dose was considered the NOEC for colony formation (Fig. 3). The non-linear model yielded a strong fit and the $1 / 2$ max-MPV

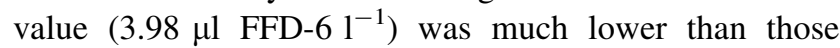
based on the other four endpoints (Table 1). 
Table $1 \mathrm{EC}_{50}$ values (in $\mu \mathrm{FFD}-61^{-1}$ ) of the green alga Scenedesmus obliquus exposed to the surfactant FFD- 6 for the means of the endpoints volume-based growth $\left(\mu_{\mathrm{VOLUME}}\right)$, cell-based growth $\left(\mu_{\mathrm{CELLS}}\right)$, chlorophyll- $a$-concentration $(\mathrm{CHL}-a)$ and photosystem II efficiency $\left(\phi_{\mathrm{PSII}}\right)$

\begin{tabular}{llr}
\hline Scenedesmus & $\mathrm{EC}_{50}($ range $)$ & $r^{2}$ \\
\hline$\mu_{\text {VOLUME }}$ & $9759(7998-10219)$ & 0.967 \\
$\mu_{\text {CELLS }}$ & $9553(5216-9683)$ & 0.875 \\
CHL- $a$ & $5086(2858-7172)$ & 0.997 \\
$\phi_{\text {PSII }}$ & $>10000$ & 0.994 \\
MPV & $3.98(3.47-4.71)$ & 0.967 \\
\hline Daphnia & LC $_{50-24 \mathrm{~h}}: \mathrm{LC}_{50-48 \mathrm{~h}}$ & $r^{2}$ \\
\hline Survival & $148(114-169): 26(13-30)$ & $0.995: 0.999$ \\
Clearance rate & $5.2(2.4-5.2)$ & 0.992
\end{tabular}

Also given are the $1 / 2$ max-MPV values for colony formation (i.e. FFD- 6 concentration causing a $50 \%$ increase in the mean particle volume, MPV, of the maximum MPV reached). For the grazer Daphnia magna the $\mathrm{LC}_{50}$-values and $\mathrm{EC}_{50}$-value for (inhibition of) the clearance rate are given, including $r^{2}$ of the non-linear regression. Range indicates $\mathrm{EC}_{50}$ values obtained from separate analysis on each replicate series

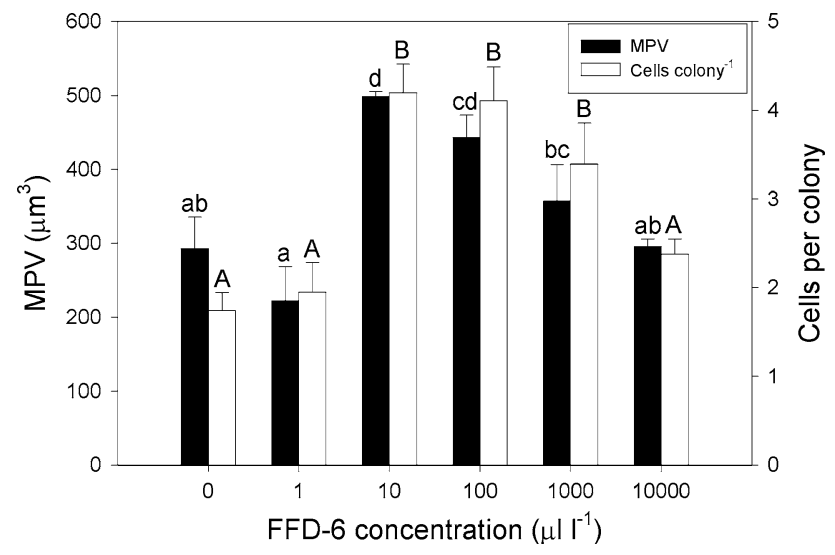

Fig. 2 Mean particle volumes (MPV in $\mu \mathrm{m}^{3}$; filled bars) and mean number of cells per colony (open bars) in Scenedesmus obliquus after $48 \mathrm{~h}$ exposure to different concentrations of the surfactant FFD-6. Error bars indicate one standard deviation $(N=3)$, while similar symbols $(a, \ldots, d$ and $A, B)$ indicate homogeneous groups that are not different at the $95 \%$ level (Tukey test)

\section{Effect of FFD-6 on Daphnia survival}

In controls and FFD- 6 concentrations of $10^{-1}$ and $10^{0}$ $\mu 11^{-1}$ between 93 and $97 \%$ of the test animals had survived after $24 \mathrm{~h}$ and $48 \mathrm{~h}$, while all had died in concentrations of $10^{3}$ and $10^{4} \mu \mathrm{FFD}-61^{-1}$. The corresponding $\mathrm{LC}_{50-24 \mathrm{~h}}$ and $\mathrm{LC}_{50-48 \mathrm{~h}}$ were 148 and $26 \mu \mathrm{l}^{-1}$, respectively (Table 1).

\section{Effect of FFD-6 on Daphnia clearance rates}

The clearance rate of similarly sized D. magna $(1.34 \pm$ $0.11 \mathrm{~mm}$ ) feeding on unicellular Scenedesmus was significantly depressed by FFD-6 (Kruskal-Wallis test: $\chi^{2}=$ 14.1; $P=0.007$ ) (Fig. 4). Dunnett's T3 test revealed three homogeneous groups: (1) $0-5$; (2) 5 and 50 and (3) $0.5,50$, 500 and $5000 \mu \mathrm{l} \mathrm{FFD-6} 1^{-1}$. The four parameter logistic

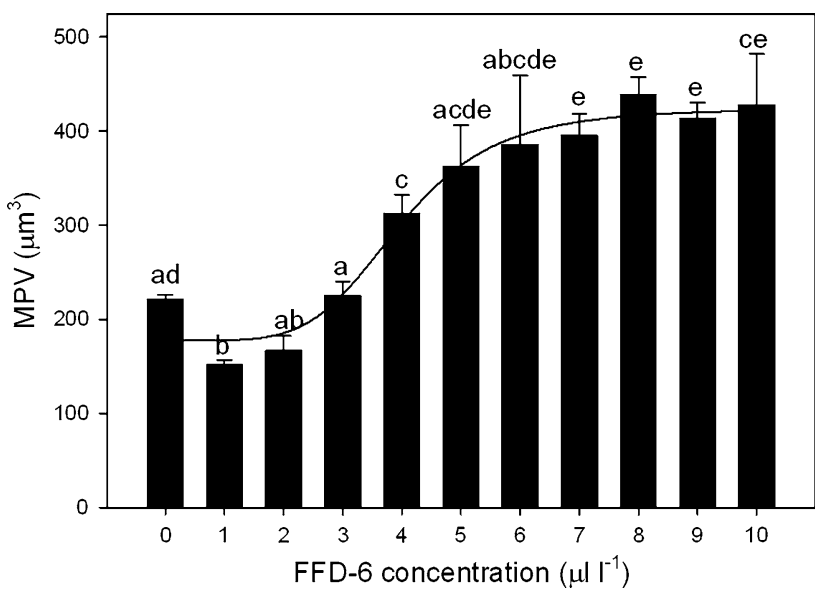

Fig. 3 Mean particle volumes (MPV, $\mu^{3}$ ) of Scenedesmus obliquus exposed to different concentrations $\left(0-10 \mu \mathrm{l}^{-1}\right)$ of the surfactant FFD-6. The solid line represents the fit of the logistic model: $\mathrm{MPV}=177.5+246.8 /\left\{1+\left([\text { FFD-6]/3.98 })^{-4.93}\right\} \quad\left(r^{2}=0.967\right)\right.$. Error bars indicate one standard deviation $(N=4)$. Similar symbols $(a, \ldots, e)$ indicate homogeneous groups that are not different at the 95\% level (Dunnett's T3 test)

model yielded an $\mathrm{EC}_{50}$-value of $5.2 \mu \mathrm{FFD}-61^{-1}$ (Fig. 4; Table 1).

\section{Effect of FFD-6 induced colonies on Daphnia clearance} rates

Juvenile D. magna (body-length $0.97 \pm 0.03 \mathrm{~mm}$ ) had significantly lower clearance rates $\left(F_{1,16}=68.1 ; P<0.001\right)$ on FFD-6 induced colonial $S$. obliquus than on the unicellular $S$. obliquus food in the controls (Fig. 5). The two-way ANOVA revealed no difference in clearance rates at the two food concentrations of 0.1 and $0.2 \mathrm{mg} \mathrm{C}^{-1}\left(F_{1,16}=1.07 ; P=\right.$ $0.317)$ and no statistical interaction effect $\left(F_{1,16}=0.65\right.$; $P=0.432)$. The control populations had on average 1.99 $( \pm 0.35)$ cells per colony, whereas the colonial populations 


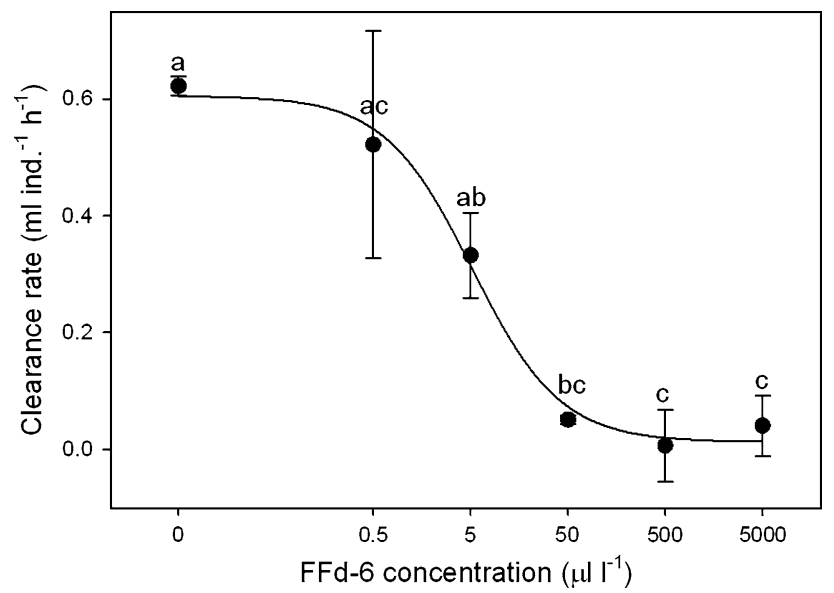

Fig. 4 Concentration-response (clearance rates, CR) curve for Daphnia magna exposed for $1.5 \mathrm{~h}$ to the anionic surfactant FFD-6 in the range $0-5000 \mu 1^{-1}$. Error bars indicate one standard deviation $(N=3)$. The solid line represents the fit of a four parameter logistic model: $\quad \mathrm{CR}=0.013+0.593 /\left\{1+([\mathrm{FFD}-6] / 5.20)^{-0.96}\right\}$ $\left(r^{2}=0.992\right)$. Similar symbols $(a, b, c)$ indicate homogeneous groups that are not different at the 95\% level (Dunnett's T3 test)

had $7.09( \pm 0.39)$ cells per colony. The corresponding MPVs were $145.1( \pm 0.9) \mu \mathrm{m}^{3}$ and $588.5( \pm 37.1) \mu \mathrm{m}^{3}$ for unicells and colonies, respectively. Length and width dimensions of unicells, four- and eight-celled colonies are given in Table 2.

\section{Discussion}

The results of the current study are in favor of the hypothesis that FFD-6 induced colonies of the green alga Scenedesmus obliquus decrease the filtering rate of the grazer Daphnia magna. The surfactant caused a shift from algal populations dominated by unicells (with average sizes of $15 \times 5 \mu \mathrm{m}$ ) to populations in which eight-celled colonies $(43 \times 29 \mu \mathrm{m})$ were most abundant. Forming large colonies moved $S$. obliquus out of the feeding window of the daphnids. This is corroborated by several other studies that have shown that the formation of colonies allowed Scenedesmus to reach sizes beyond the ingestion capacity of the grazers, which was reflected in lower clearance rates of Daphnia on colonial Scenedesmus compared to unicells (Hessen and Van Donk 1993; Lürling and Van Donk 1996; Lürling et al. 1997; Lürling 2003).

The anionic surfactant FFD-6 promoted the formation of colonies in $S$. obliquus at concentrations far below those that inhibited growth, which is in concordance with previous studies (Lürling and Beekman 2002; Lürling 2006). The $1 / 2$ max-MPV value of $3.98 \mu \mathrm{l} \mathrm{FFD-6} 1^{-1}$ for colony induction was far below the NOEC value of $10^{3} \mu$ FFD$61^{-1}$ for growth inhibition. Thus, the morphological appearance of Scenedesmus was a more sensitive endpoint than the traditionally determined growth inhibition.
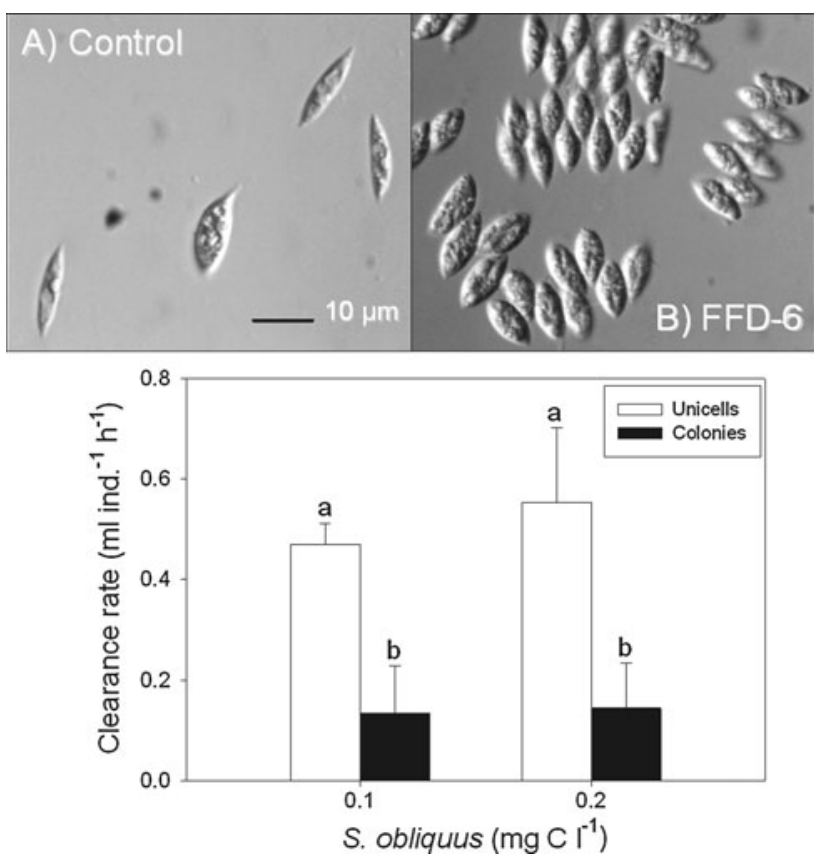

Fig. 5 Morphological appearance of the green alga Scenedesmus obliquus after $48 \mathrm{~h}$ in the absence (upper left panel $\mathbf{a}$; control) and presence of the anionic surfactant FFD-6 (upper right panel, b; FFD6). The lower panel c presents the mean clearance rates of juvenile Daphnia magna on the food two types (unicells from controls; open bars, and colonies from FFD-6 treatments; filled bars) at two food concentrations. Error bars indicate one standard deviation $(N=5)$. Similar symbols $(a, b)$ indicate homogeneous groups that are not different at the $95 \%$ level (Tukey test)

The tendency of higher cell multiplication rates in the range $0-10 \mu \mathrm{l}$ FFD- $61^{-1}$ (see Fig. 1) coincided with the formation of colonies. However, growth in terms of biomass acquisition (biovolume-based) was not affected. This phenomenon has also been observed for the grazer-induced formation of colonies in Scenedesmus (Lampert et al. 1994). For example, the regression obtained for the grazerinduced formation of colonies between volume and cells per colony $[\log (\mathrm{MPV})=2.127+0.726 \times \log \quad($ cells colony $^{-1}$ ); Lampert et al. 1994] is in close match with that of the current study $[\log (\mathrm{MPV})=2.235+0.662 \times \log$ (cells colony $^{-1}$ )]. In both regressions, the slope is less than one, which indicates that individual cell sizes decreased with increasing colony size.

The colonies were formed at doses of $10-10^{3} \mu \mathrm{FFD}$ $61^{-1}$, but not at $10^{4} \mu \mathrm{F}$ FFD- $61^{-1}$. At the highest dose, FFD-6 impeded growth and the reduced growth rate implied that resources needed for the production of daughter cells, and thus potentially colonies, were acquired at rates too low to trigger the unicell-colony transformation within the experimental period. Those Scenedesmus cultures would theoretically need about 4-5 days to acquire sufficient resources to become colonial too. A similar observation has been made when Scenedesmus was 
Table 2 Length and width (means $\pm 1 \mathrm{SD}$, in $\mu \mathrm{m}$ ) of unicells in controls and FFD-6 induced four- and eight-celled colonies of Scenedesmus obliquus

\begin{tabular}{llrl}
\hline & \multicolumn{1}{l}{ Length } & \multicolumn{1}{l}{ Width } & $N$ \\
\hline Unicells & $14.9 \pm 1.7$ & $5.2 \pm 0.8$ & 20 \\
Four-celled & $20.8 \pm 3.6$ & $18.2 \pm 2.5$ & 20 \\
Eight-celled & $43.7 \pm 8.4$ & $29.0 \pm 4.7$ & 20 \\
\hline
\end{tabular}

exposed simultaneously to FFD-6 and the growth-(photosynthesis) inhibiting herbicide metribuzin (Lürling 2011).

The $\mathrm{EC}_{50}$ value for (inhibition of) the clearance rate of D. magna was $5.2 \mu \mathrm{lFFD}-61^{-1}$, which was lower than the LC $_{50-48 \mathrm{~h}}\left(26 \mu \mathrm{lFD}-6 \mathrm{l}^{-1}\right)$. This fits in a consistent pattern as for several other toxicants, such as metals and pesticides, $\mathrm{EC}_{50}$ values for feeding inhibition were 5-130 times lower than LC $_{50}$ values (Gliwicz and Sieniawska 1986; Hartgers et al. 1999; McWilliam and Baird 2002). Since acute studies might provide a good indication of population level effects using an extrapolation factor of 10 between the $\mathrm{LC}_{50}$ and the NOEC (Roex et al. 2000), extrapolation would yield a chronic Daphnia population level NOEC of $2.6 \mu \mathrm{lFF}-6 \mathrm{1}^{-1}$, which is about $1.5 \mathrm{mg}$ FFD-6 $1^{-1}$. Such chronic NOEC value would be lower than the $\mathrm{EC}_{50}$ value for feeding inhibition, but in good agreement with reported NOEC values for chronic exposure of Daphnia to anionic surfactants (Lewis 1991). Nonetheless, prolonged exposure to a toxicant might also further depress Daphnia feeding rates (Hartgers et al. 1999). The acute $\mathrm{LC}_{50-48 \mathrm{~h}}(26 \mu \mathrm{l}$ FFD-6 $1^{-1}$, i.e. $\sim 15 \mathrm{mg} \mathrm{l}^{-1}$ ) was also in good agreement with literature data for acute toxicity of LAS to D. magna 0.7-270 $\mathrm{mg} \mathrm{l}^{-1}$ (Verge and Moreno 2000; Verge et al. 2001; Hodges et al. 2006), and D. similis; $\sim 14 \mathrm{mg}^{-1}$ for C12-LAS (Da Silva Coelho and Rocha 2010).

The similarity between the $1 / 2$ max-MPV value and the feeding $\mathrm{EC}_{50}$ value indicates that lower Daphnia clearance rates could also result from FFD-6 transported from the algal suspensions into the grazing vials. However, the low food concentrations employed in the grazing experiment ensured that FFD-6 concentrations were below the NOEC value for feeding inhibition. According to our results, it can be expected that if the organisms are co-cultured at FFD-6 concentrations eliciting the morphological response in $S$. obliquus, there will also be a direct adverse effect on the feeding activity of the daphnids. Surfactants influence the surface chemistry of food particles and an increase in wettability has been shown causing more food particles to escape the filtering apparatus of the Daphnia (Gerritsen and Porter 1982). Therefore, several mechanisms may act in concert in exerting adverse effects of FFD-6 on the energy flow from $S$. obliquus to D. magna. Hence, the overall effect on feeding inhibition might have been underestimated in our experiments. Inasmuch as in our experiment with FFD-6 induced colonies a direct FFD-6 effect on clearance rates can be refuted, the most probable explanation for the lower clearance rates of D. magna is that they were caused by the altered morphology of the algal food rather than by toxicity.

The effects of FFD-6 on Scenedesmus morphology and grazer feeding efficiency point towards a reduction of the energy-flow along the food chain for the ScenedesmusDaphnia system. Lower food intake by daphnids is reflected in lower reproduction and reduced population growth (Lynch 1989), which has also been demonstrated for small-bodied Daphnia on a feed of Scenedesmus colonies (Lürling and Van Donk 1996; Lürling et al. 1997). In this particular plankton system, Scenedesmus responds with the formation of protective colonies to a high threat of being consumed by Daphnia, which is advertised by chemical cues released from the grazers (e.g. Lürling 2003; Von Elert and Franck 1999). This grazer-induced formation of protective colonies is only activated when needed, to avoid unnecessary costs. Therefore, a reliable cue is an important requirement to make chemically induced defenses an evolutionary stable strategy (Harvell 1990) and a stabilizing factor in predator-prey interactions (Lürling et al. 2005). Although the anti-grazing response has also been observed in the green algae Chlorella (Boraas et al. 1998), Chlamydomonas (Lürling and Beekman 2006) and Coelastrum (Van Donk et al. 1999), the marine prymnesiophyte Phaeocystis (Tang 2003) and the cyanobacteria Microcystis (Yang et al. 2006) and Cyanobium (Jezberová and Komarková 2007), it remains unknown how these organisms respond to surfactants. Moreover, results from simple two species plankton systems cannot be extrapolated to multi-species systems or to natural communities (Kratina et al. 2007). Because in nature a wide variety of food items will be available to the grazers, further research should be directed towards a scaling up of experiments to more complex systems to elucidate the community level consequences.

Recently, the chemical nature of the natural colonyinducing chemicals released from Daphnia has been elucidated and the active substances were identified as different aliphatic sulfates (Yasumoto et al. 2005; 2006; 2008a, b). These compounds are closely related to commonly used manmade anionic surfactants. It is therefore not surprising that two commercially available anionic surfactants (sodium dodecyl sulphate and FFD-6) triggered the unicell-colony transformation in $S$. obliquus as did centrifuged water from a zooplankton culture; and in that way the surfactant effect resembled the natural-induced colony formation (Lürling and Beekman 2002; Yasumoto et al. 2005).

The FFD-6-mimicry of the natural chemical messenger might be far from a reliable proxy of the actual predation 
risk as advertised by the natural cue. When colonies are induced under low grazing pressure, the benefit, a reduced mortality from grazing, will not outbalance the costs, such as enhanced sinking out of the euphotic zone (Lürling and Van Donk 2000). Consequently, those surfactant-induced colonies can be viewed as maladapted phenotypes with potentially adverse effects on population dynamics of the algae and grazers, where the later might suffer from aggravated anorexia. However, it should be noted that FFD-6 is mainly used in standard spectrophotometric analysis of phosphorus in water (e.g. EPA 1996; Skalar 2002). Thus, environmental concentrations of this particular surfactant will be extremely low. However, FFD-6 belongs to the class of linear alkylbenzene sulfonates (LAS), which are the major anionic surfactants currently on the global market. The structural similarity of many LAS with the 13 different aliphatic sulfates and sulfamates, which have been identified as natural colony-inducing compounds (Yasumoto et al. 2008b), might point toward a more widespread mimicry than solely restricted to sodium dodecyl sulfate and FFD-6. Hence, further research should be directed to study if colony-induction in Scenedesmus is a more general feature of anionic surfactants. In general, anionic surfactant concentrations in surface water are below $100 \mu \mathrm{g} 1^{-1}$ (e.g. Ding et al. 1999; Lara-Martín et al. 2008), but overall these surfactants also cause growth inhibition in green algae at concentrations of an order of magnitude lower than that for FFD-6 (Pavlić et al. 2005).

The surfactant triggered a response in Scenedesmus similar to the natural grazing-associated chemicals, and through effects on Daphnia feeding rates it might also affect production/release of chemical messengers by the grazers. Such disruption of the natural info-chemical system between organisms shows high similarity with endocrine-disrupters that disturb the normal endocrine feedback inside organisms. Disturbance of information exchange between organisms, such as mimicry, amplification or inhibition of natural signals, has the potential of causing organisms to behave/respond maladaptive. Negative effects on key species, such as Daphnia, will not only influence their population dynamics, but could also be spread out over the entire system, through biological interactions (Hanazato 1999). The information component in those interactions is often of major importance in which chemicals are the most dominant form of information carriers. Organisms intensively use such chemical messengers to locate food, find a mate, recognize close kin, mark a territory or detect enemies (Dicke and Takken 2006). With increasing evidence that aquatic organisms exchange information through chemical messengers, the potential disturbance by anthropogenic chemicals, presents an ecological risk (Lürling and Scheffer 2007), which is not covered by standard toxicity tests.
Acknowledgments The research of ML was made possible by a Fellowship from the Royal Netherlands Academy of Arts and Sciences.

Open Access This article is distributed under the terms of the Creative Commons Attribution Noncommercial License which permits any noncommercial use, distribution, and reproduction in any medium, provided the original author(s) and source are credited.

\section{References}

Barata C, Alañon P, Gutierrez-Alonso S, Riva MC, Fernández C, Tarazona JV (2008) A Daphnia magna feeding bioassay as a cost effective and ecological relevant sublethal toxicity test for Environmental Risk Assessment of toxic effluents. Sci Tot Env 405:78-86

Boraas ME, Seale DB, Boxhorn JE (1998) Phagotrophy by a flagellate selects for colonial prey: a possible origin of multicellularity. Evol Ecol 12:153-164

Christensen BT, Lauridsen L, Ravn HW, Bayley M (2005) A comparison of feeding efficiency and swimming ability of Daphnia magna exposed to cypermethrin. Aquat Toxicol 73:210-220

Da Silva Coelho K, Rocha O (2010) Assessment of the potential toxicity of a linear alkylbenzene sulfonate (LAS) to freshwater animal life by means of cladoceran bioassays. Ecotoxicology 19:812-818

Dicke M, Takken W (2006) Chemical ecology. From gene to ecosystem. Wageningen UR Frontis Series 16. Springer, The Netherlands

Ding W-S, Tzing S-H, Lo J-H (1999) Occurrence and concentrations of aromatic surfactants and their degradation products in river waters of Taiwan. Chemosphere 38:2597-2606

EPA (1996) Recommended guidelines for sampling and analyses in the Chesapeake Bay monitoring program. EPA 903-R-96-006

Fernández-Casselderry A, Ferrando MD, Andreu-Moliner E (1994) Effect of sublethal concentrations of pesticides on the feeding behavior of Daphnia magna. Ecotox Environ Saf 27:82-89

Gerritsen J, Porter KG (1982) The role of surface chemistry in filter feeding by zooplankton. Science 216:1225-1227

Gliwicz MZ, Sieniawska A (1986) Filtering activity of Daphnia in low concentrations of a pesticide. Limnol Oceanogr 31:1132-1138

Hanazato T (1999) Anthropogenic chemicals (insecticides) disturb natural organic chemical communication in the plankton community. Environ Poll 105:137-142

Hartgers EM, Heugens EHW, Deneer JW (1999) Effect of lindane on the clearance rate of Daphnia magna. Arch Environ Contam Toxicol 36:399-404

Harvell CD (1990) The ecology and evolution of inducible defenses. Q Rev Biol 65:323-340

Hessen DO, Van Donk E (1993) Morphological changes in Scenedesmus induced by substances released from Daphnia. Arch Hydrobiol 127:129-140

Hodges G, Roberts DW, Marshall SJ, Dearden JC (2006) The aquatic toxicity of anionic surfactants to Daphnia magna - a comparative QSAR study of linear alkylbenzene sulphonates and ester sulphonates. Chemosphere 63:1443-1450

Jezberová J, Komarková J (2007) Morphological transformation in a freshwater Cyanobium sp. induced by grazers. Environ Microbiol 9:1858-1862

Kersting K, van der Honing H (1981) Effect of the herbicide dichlobenil on the feeding and filtering rate of Daphnia magna. Verh Int Verein Limnol 21:1135-1140

Kratina P, Vos M, Anholt BR (2007) Species diversity modulates predation. Ecology 88:1917-1923 
Lampert W (1987) Feeding and nutrition in Daphnia. In: Peters RH, De Bernardi R (eds) “Daphnia” Memorie dell'Istituto Italiano di Idrobiologia, vol 45, pp 143-192

Lampert W, Rothhaupt KO, von Elert E (1994) Chemical induction of colony formation in a green alga (Scenedesmus acutus) by grazers (Daphnia). Limnol Oceanogr 39:1543-1550

Lara-Martín PA, Gómez-Parra A, González-Mazo E (2008) Sources, transport and reactivity of anionic and non-ionic surfactants in several aquatic ecosystems in SW Spain: a comparative study. Environ Poll 156:36-45

Lewis MA (1991) Chronic and sublethal toxicities of surfactants to aquatic animals: a review and risk assessment. Wat Res 25:101-113

Lürling M (2003) Phenotypic plasticity in the green algae Desmodesmus and Scenedesmus with special reference to the induction of defensive morphology. Ann Limnol Int J Lim 39:85-101

Lürling M (2006) Effects of a surfactant (FFD-6) on Scenedesmus morphology and growth under different nutrient conditions. Chemosphere 62:1351-1358

Lürling M (2011) Metribuzin impairs the unicell-colony transformation in the green alga Scenedesmus obliquus. Chemosphere 82:411-417

Lürling M, Beekman W (2002) Extractable substances (anionic surfactants) from membrane-filters induce morphological changes in the green alga Scenedesmus obliquus (Chlorophyceae). Environ Toxicol Chem 21:1213-1218

Lürling M, Beekman W (2006) Palmelloids formation in Chlamydomonas reinhardtii: defence against rotifer predators? Ann Limnol Int J Lim 42:65-72

Lürling M, Scheffer M (2007) Info-disruption: pollution and the transfer of chemical information between organisms. Trends Ecol Evol 22:374-379

Lürling M, Van Donk E (1996) Zooplankton-induced unicell-colony transformation in Scenedesmus acutus and its effect on growth of herbivore Daphnia. Oecologia 108:432-437

Lürling M, Van Donk E (2000) Grazer-induced colony formation in Scenedesmus: costs of being colonial? Oikos 88:111-118

Lürling M, Verschoor AM (2003) $\mathrm{F}_{0}$-spectra of chlorophyll fluorescence for the determination of zooplankton grazing. Hydrobiologia 491:145-157

Lürling M, De Lange HJ, Van Donk E (1997) Changes in food quality of the green alga Scenedesmus induced by Daphnia infochemicals: biochemical composition and morphology. Freshwater Biol 38:619-628

Lürling M, Arends H, Beekman W, Vos M, Van der Stap I, Mooij WM, Scheffer M (2005) Effect of grazer-induced morphological changes in the green alga Scenedesmus obliquus on growth of the rotifer Brachionus calyciflorus. Verh Int Verein Limnol 29:698-703

Lynch M (1989) The life-history consequences of resource depression in Daphnia pulex. Ecology 70:246-256

McWilliam RA, Baird DJ (2002) Postexposure feeding depression: a new toxicity endpoint for use in laboratiry studies with Daphnia magna. Environ Toxicol Chem 21:1198-1205

Pavlić Ž, Vidaković-Cifrek Ž, Puntarić D (2005) Toxicity of surfactants to green microalgae Pseudokirchneriella subcapitata and Scenedesmus subspicatus and to marine diatoms Phaeodactylum tricornutum and Skeletonema costatum. Chemosphere 61:1061-1068

Pestana JLT, Loureiro S, Baird DJ, Soares AMVM (2010) Pesticide exposure and inducible antipredator responses in the zooplankton grazer, Daphnia magna Straus. Chemosphere 78:241-248
Roex EWM, Van Gestel CAM, Van Wezel AP, Van Straalen NM (2000) Ratios between acute aquatic toxicity and effects on population growth rates in relation to toxicant mode of action. Environ Toxicol Chem 19:685-693

Scheffer M, Hosper SH, Meijer ML, Moss B (1993) Alternative equilibria in shallow lakes. Trends Ecol Evol 8:275-279

Scheffer M, Carpenter SR, Foley JA, Folke C, Walker B (2001) Catastrophic shifts in ecosystems. Nature 413:591-596

Skalar (2002) Skalar methods: phosphate in wastewater; Skalar, The Netherlands

Tang KW (2003) Grazing and colony size development in Phaeocystis globosa (Prymnesiophyceae): the role of a chemical signal. J Plankton Res 25:831-842

Tollrian R (1993) Neckteeth formation in Daphnia pulex as an example of continuous phenotypic plasticity: morphological effects of Chaoborus kairomone concentration and their quantification. J Plankton Res 15:1309-1318

Tollrian R, Dodson SI (1999) Inducible defenses in cladocera: constraints, costs, and multiple predator environments. In: Tollrian R, Harvell CD (eds) The ecology and evolution of inducible defenses. Princeton University Press, New Jersey, pp 177-202

Van Donk E, Lürling M, Lampert W (1999) Consumer induced changes in phytoplankton, inducibility, costs, benefits and the impact on grazers. In: Tollrian R, Harvell CD (eds) The ecology and evolution of inducible defenses. Princeton University Press, New Jersey, pp 89-103

Verge C, Moreno A (2000) Effects of anionic surfactants on Daphnia magna. Tenside Surf Det 37:172-175

Verge C, Moreno A, Bravo J, Berna JL (2001) Influence of water hardness on the bioavailability and toxicity of linear alkylbenzene sulphonate LAS). Chemosphere 44:1749-1757

Villarroel MD, Ferrando MD, Sancho E, Andreu E (1999) Daphnia magna feeding behavior after exposure to tetradifon and recovery from intoxication. Ecotox Environ Saf 44:40-46

Von Elert E, Franck A (1999) Colony formation in Scenedesmus: grazer-mediated release and chemical features of the infochemical. J Plankton Res 21:789-804

Yang Z, Kong F, Shi X, Cao H (2006) Morphological response of Microcystis aeruginosa to grazing by different sorts of zooplankton. Hydrobiologia 563:225-230

Yasumoto K, Nishigami A, Yasumoto M, Kasai F, Okada Y, Kusumi T, Ooi T (2005) Aliphatic sulfates released from Daphnia induce morphological defense of phytoplankton: isolation and synthesis of kairomones. Tetrahedron Lett 46:4765-4767

Yasumoto K, Nishigami A, Kasai F, Kusumi T, Ooi T (2006) Isolation and absolute configuration determination of aliphatic sulfates as the Daphnia kairomones inducing morphological defense of a phytoplankton. Chem Pharm Bull 54:271-274

Yasumoto K, Nishigami A, Aoi H, Tsuchihashi C, Kasai F, Kusumi $\mathrm{T}$, Ooi T (2008a) Isolation and absolute configuration determination of aliphatic sulfates as the Daphnia kairomones inducing morphological defense of a phytoplankton-Part 2. Chem Pharm Bull 56:129-132

Yasumoto K, Nishigami A, Aoi H, Tsuchihashi C, Kasai F, Kusumi $\mathrm{T}$, Ooi $\mathrm{T}$ (2008b) Isolation of new aliphatic sulfates and sulfamate as the Daphnia kairomones inducing morphological change of a phytoplankton Scenedesmus gutwinskii. Chem Pharm Bull 56:133-136 